\title{
Helicobacter Pylori Tailored Treatment in Children: Tissue Culture and Sensitivity Based
}

\author{
BEHAIRY E. BEHAIRY, M.D.*; NERMIN M. ADAWY, M.D.*; TAWFIK M. ABD ELMOTALEB, M.D.**; \\ DALIA H. ABDULLAH ZAYED, M.D.*** and HOSAM-ELDIN M. BASIOUNY, M.D.* \\ The Departments of Pediatric Hepatology, Gastroenterology \& Nutrition* and Microbiology \& Immunology**, \\ National Liver Institute, Menoufia University, Shebin El-Koom, Menoufia and The Department of Pediatric Hepatology, \\ Gastroenterology \& Nutrition, Rahmaniyah Central Hospital, Rahmaniyah, Behara***, Egypt
}

\begin{abstract}
Background: Helicobacter pylori (H. pylori) is one of the most common chronic bacterial infections in the world, and it is currently estimated that approximately half of the world's population is infected with the bacterium. The correct diagnosis and effective treatment of $\mathrm{H}$. pylori gastric infection are essential in controlling this condition. The available diagnostic methods have advantages and limitations related to factors such as age of patients, technical difficulty level, costs and extensive accessibility in hospitals. The eradication therapy of $\mathrm{H}$. pylori infection is still a challenge for gastroenterologists. One of the main causes of failure in $\mathrm{H}$. pylori eradication is antibiotic resistance. Biopsy cultures are the most widely used methods among the antimicrobial susceptibility tests.
\end{abstract}

Aim of Study: The aim of this work was to determine the proper regiment of $\mathrm{H}$. Pylori treatment according to gastroduodenal tissue culture and antibiotic sensitivity.

Patients and Methods: This study included 50 patients with Helicobacter Pylori Ag positive stools and positive occult blood in stool. Their age ranged from 1.5 to 17 years old, $60 \%$ of them were female. 37 patients showed positive gastric and duodenal cultures and received treatment according to results of cultures.

Results: Antibiotic sensitivity of gastric culture shows that Levofloxacin had the highest antibiotic sensitivity (93.5\%), followed by clarithromycin and amoxicillin in (77\%) and $(67.7 \%)$ respectively. But, $100 \%$ of cases were resistant to the Metronidazole. In duodenal culture, Levofloxacin had the highest antibiotic sensitivity (96.4\%), followed by, clarithromycin and amoxicillin in (71.4\%) for each. But, $100 \%$ of cases were resistant to the Metronidazole. All patientsreceived PPI and Levofloxacin, while about 59\% and 30\% of patients received Amoxacillin and Clarithromycin respectively.

Conclusion: Treatment of Helicobacter Pylori should be tailored according to tissue culture and sensitivity.

Correspondence to: Dr. Hosam-Eldin M. Basiouny, E-Mail: Hosambasiouny@yahoo.com
Key Words: Helicobacter pylori-Levofloxacin-Clarithromycin-Amoxicillin - Gastric cultures - Duodenal cultures.

\section{Introduction}

HELICOBACTER pylori (H. Pylori) was first identified in gastric biopsy antral specimens by Dr. Barry Marshall and his mentor, Dr. Robin Warren, in the early 1980s [1]. Approximately 10\% of infected individuals develop overt clinical disease while $90 \%$ remain subclinical and the infection can persist throughout life if untreated. H. Pylori has 20 recognized strains that have been implicated in many diseases including duodenal ulcers, gastric ulcers, adenocarcinoma of the distal stomach, Mucosa-Associated Lymphoid Tissue (MALT) lymphoma, diabetes mellitus, cardiovascular disease and autoimmune disease [2]. The goal of $\mathrm{H}$. Pylori treatment is complete elimination of the organism. Once this is achieved, re-infection rates are low, thus the benefit of treatment is durable. The main reasons for eradication failure of $\mathrm{H}$. Pylori infection include antibiotic resistance, poor compliance and rapid metabolism of Proton Pump Inhibitor (PPIs). Infection with H. Pylori is still the most common bacterial infection in humans, despite the significant worldwide decrease in its incidence and prevalence recorded in recent years

\begin{tabular}{ll}
\hline Abbreviations \\
H. Pylori : Helicobacter Pylori. \\
MALT $:$ Mucosa-Associated Lymphoid Tissue. \\
PPIs $\quad$ : Proton Pump Inhibitor. \\
AMO : Amoxacillin. \\
CLA $\quad$ : Clarithromycin. \\
ALT $\quad:$ Alanine Transaminase. \\
AST $\quad$ Aspartate Transaminase.
\end{tabular}


[3] . In children H. Pylori infection may lead to chronic inflammation of the gastric mucosa, peptic ulcers, gastric erosions, MALT lymphoma, in addition to extra gastric complications, such as irondeficiency anemia [4]. The first-line treatments currently available for children infected with $\mathrm{H}$. Pylori are various combinations of PPI with antibiotics including Amoxacillin (AMO), macrolides, and/or imidazoles [5]. In the last decade, the eradication rates using these schemes have declined and have led to recommendations for higher dosages and longer duration of therapy or alternative regimens, including three instead of two different antibiotics, either sequentially or concomitantly. The low success rates are essentially due to the increasing resistance rates to macrolides and to a lesser extent imidazoles [6]. Continuous surveillance of both antimicrobial resistance of $\mathrm{H}$. Pylori as well as different treatment modalities success rate is crucial for improving and developing optimal treatment. Clarithromycin (CLA)-based therapy is still the mainstay for $\mathrm{H}$. Pylori eradication [7] However, the pediatric population is prone to development of CLA resistance due to a high burden of respiratory tract infections, for which macrolide antibiotics are often prescribed. For this reason, some suggest that CLA should not be used for $\mathrm{H}$. Pylori eradication unless susceptibility has been confirmed [4]

\section{Patients and Methods}

Patients: This study included 50 patients with Helicobacter Pylori Ag positive stools and positive occult blood in stool recruited from Pediatric Hepatolology, Gastroenterology and Nutrition Department, National Liver Institute, Menoufia University from August 2018 - July 2020. Excluding criteria were the use of proton pump inhibitors or H2-receptor antagonists and antibiotics as well as non-steroidal anti-inflammatory drugs or steroidal treatment 2 weeksbefore the beginning of the study), concomitant severe disease (heart, lungs, kidney and endocrine diseases). A signed informed consent was obtained from the parents of all patients before enrollment in this study. The study was approved by the Research Ethics Committee of National Liver Institute. All patients were subjected to the following: Full history taking, thorough clinical examination and the following investigations: Complete blood count, AST, ALT, serum total protein, serum albumin, abdominal US. Upper endoscopy was performed after at least 8 hours fasting, young infants were supported by intravenous fluid during fasting. Sedation using midazolam $(0.3 \mathrm{mg} / \mathrm{Kg} /$ dose $)$ was sometimes used followed by propofol (diprivan) in a dose of $(1 \mathrm{mg} / \mathrm{kg}$ IV). The child was put on his left lateral position; endoscopy was introduced through mouth till it reaches the second part of the duodenum. Complete examination for esophagus, stomach and duodenum using Olympus GIF-H170 device with light source CLVU40 and Processor C.V 240. During examination, oxygen saturation and pulse rate were continuously monitored using pulse oximetry. Biopsies were taken by EP Flex biopsy specimens for histology (one for the antrum, one for the corpus and one from the duodenum). One sample from the antrum was used for rapid urease test. Two additional biopsies were taken from the antrum and two from the duodenum for bacterial culture. The samples were placed into separate vials, previously identified, containing the appropriate medium for each test.

Bacterial culture the biopsy specimens collected for bacterial culture were transported in commercial selective transport H. Pylori medium, Portagerm pylori (BioMérieux SA, Marcy l'Etoile, France), and were inoculated after a few hours onto selective medium pylori agar (BioMérieux Italia). The plates were incubated under microaerobic condition at $37^{\circ}$ for 72 hours. Once incubated, the colonies resembling $\mathrm{H}$. Pylori were identified by Gram stain and by oxidase, catalase and urease tests. Suspensions from the primary plates were prepared in sterile solution to perform an E-test on pylori agar. An agar plate was streaked in three directions with a swab dipped into each bacterial suspension to produce a lawn of growth; an E-test strip (E-test; AB Biodisk, Solna, Sweden) was placed each onto separate plates, which was immediately incubated in a microaerobic atmosphere at $37^{\circ}$ for 72 hours. Isolated strains were tested for amoxicillin, clarithromycin, metronidazole and levofloxacin resistance following the recommendations of the European Committee on Antimicrobial Susceptibility Testing.

Histology a biopsy of the gastric body, antrum and duodenal biopsies were fixed in a solution of formaldehyde $10 \%$. Subsequently, mucosa samples were processed, following the usual steps of dehydration and paraffin embedding. Two stains were used for histological study: Haematoxylin-eosin and Giemsa. Gastritis was graded according to the Sydney system.

\section{Treatment:}

37 patients showed positive gastric and duodenalcultures and receivedtreatment according to results of cultures.

- 23 patient received sequential therapy (12 patients received amoxicillin $50 \mathrm{mg} / \mathrm{kg} /$ day and esome- 
prazole $0.5 \mathrm{mg} / \mathrm{kg} / \mathrm{day}$ for 5 days then levofloxacin on $16 \mathrm{mg} / \mathrm{kg} /$ day and esomeprazole $0.5 \mathrm{mg} / \mathrm{kg} / \mathrm{day}$ for 5 days followed by esomeprazole $0.5 \mathrm{mg} / \mathrm{kg} /$ day for another 15 days) and (11 patients received clarithromycin $15 \mathrm{mg} / \mathrm{kg} /$ day and esomeprazole $0.5 \mathrm{mg} / \mathrm{kg} / \mathrm{day}$ for 5 days then levofloxacin on $16 \mathrm{mg} / \mathrm{kg} /$ day and esomeprazole $0.5 \mathrm{mg} / \mathrm{kg} /$ day for 5 days followed by esomeprazole $0.5 \mathrm{mg} / \mathrm{kg} /$ day for another 15 days).

- 10 patients received combined therapy (9 patients received amoxicillin $50 \mathrm{mg} / \mathrm{kg} / \mathrm{day}$, esomeprazole $0.5 \mathrm{mg} / \mathrm{kg} /$ day and levofloxacin on $16 \mathrm{mg} / \mathrm{kg} /$ day for 15 days followed by esomeprazole $0.5 \mathrm{mg} / \mathrm{kg} /$ day for another 15 days) and (one patient received clarithromycin $15 \mathrm{mg} / \mathrm{kg} / \mathrm{day}$, esomeprazole 0.5 $\mathrm{mg} / \mathrm{kg} /$ day and levofloxacin on $16 \mathrm{mg} / \mathrm{kg} / \mathrm{day}$ for 15 days followed by esomeprazole $0.5 \mathrm{mg} / \mathrm{kg} / \mathrm{day}$ for another 15 days).

- 4 patients received levofloxacin on $16 \mathrm{mg} / \mathrm{kg} / \mathrm{day}$ and esomeprazole $0.5 \mathrm{mg} / \mathrm{kg} /$ day for 15 days followed by esomeprazole $0.5 \mathrm{mg} / \mathrm{kg} /$ day for another 15 days).

Follow-up: After one month from the end of treatment, stool Ag of helicobacter pylori was requested for all patients despite of improvement of patients weight, appetite, and improvement of abdominal pain in 34 patients from 37 who received treatment. stool Ag of helicobacter pylori was positive in 9 patients, so occult blood in stool was requested. occult blood was positive only in those patients who not improved and still suffering from abdominal pain, another endoscopy was done and another cultureswere taken, two patients showed positive culture and the third one showed negative culture and negative histopathologyfindings.

\section{Statistical methods:}

Data were analyzed using the SPSS (Statistical Package for Social Science) program version 21, SPSS Inc., Chicago, Illinois, USA. Qualitative data were expressed as frequency and percentage. Quantitative data were shown as mean \pm Standard Deviation $(\mathrm{SD})$.

\section{Results}

This study included 50 patients with Helicobacter Pylori Ag positive stools and positive occult blood in stool their age ranged from 1.5 to 17 years old, $60 \%$ of them were female and majority of patients had a history of abdominal pain, loss of appetite, vomiting and treatment failure to Pylori (96\%) and (64\%) 52\% and 48\% respectively. Mean $\pm \mathrm{SD}$ of $\mathrm{Hb}$ was $11.52 \pm 1.23$, mean $\pm \mathrm{SD}$ of AST was $30.05 \pm 60.17$, mean \pm SD of ALT was $32.90 \pm$
50.49 , mean \pm SD of total protein was $6.52 \pm 0.76$ and mean \pm SD of serum albumin was $4.47 \pm 0.42$ all were with normal rang. Majority of patients (90\% \& 92\%) had normal liver and spleen size respectively, while $8 \%$ suffered from mesenteric lymphadenopathy. By endoscopic examination gastritis, esophagitis, incompetentcardia, gastric nodularity and hiatus hernia were detected in $(98 \%)$, $(36 \%),(32 \%),(26 \%)$ and $(22 \%)$ respectively. Histopathological examination of gastric and duodenal biopsies reveled that, lymphocytes infiltrations plasma cellsinfiltrations epithelial edema and eosinophilsinfiltrations were detected in $(90 \%),(88 \%)$, $(86 \%)$ and $(86 \%)$ for eachrespectively, while activity of H. Pylori ware found in only in $(60 \%)$ of patients. No dysplasia or metaplasia were found.

After the end of treatment patientsweight and appetite improved with improvement of abdominal pain.

Table (1): Histopathologicalfindings of gastric and duodenal biopsies.

\begin{tabular}{llllc}
\hline & \multicolumn{4}{c}{ Number = 50 } \\
\cline { 2 - 5 } Histopathology & \multicolumn{2}{c}{ Present } & \multicolumn{2}{c}{ Absent } \\
\cline { 2 - 5 } findings & $\mathrm{N}$ & $\%$ & $\mathrm{~N}$ & $\%$ \\
\hline Epithelial edema & 43 & 86.0 & 7 & 14.0 \\
Lymphocytes & 45 & 90.0 & 5 & 10.0 \\
Esinophils & 43 & 86.0 & 7 & 14.0 \\
Plasma cells & 44 & 88.0 & 6 & 12.0 \\
Polymorphs & 23 & 46.0 & 27 & 54.0 \\
H pylori & 42 & 84.0 & 8 & 16.0 \\
Activity of H. Pylori & 30 & 60.0 & 20 & 40.0 \\
Metaplasia & 0 & 0.0 & 50 & 100.0 \\
Dysplasia & 0 & 0.0 & 50 & 100.0 \\
\hline
\end{tabular}

Table (2): Result of gastric and duodenal culture.

\begin{tabular}{|c|c|c|c|c|}
\hline \multirow{3}{*}{$\begin{array}{l}\text { Result of gastric and/or } \\
\text { duodenal culture }\end{array}$} & \multicolumn{4}{|c|}{ Number $=50$} \\
\hline & \multicolumn{2}{|c|}{ Growth } & \multicolumn{2}{|c|}{ No growth } \\
\hline & $\mathrm{N}$ & $\%$ & $N$ & $\%$ \\
\hline Gastric.culture & 31 & 62.0 & 19 & 38.0 \\
\hline Duodenal.culture & 28 & 56.0 & 22 & 44.0 \\
\hline Gastric and duodenal culture & 37 & 74.0 & 13 & 26.0 \\
\hline
\end{tabular}

Table (3): Antibiotic sensitivity of gastric culture.

\begin{tabular}{|c|c|c|c|c|}
\hline \multirow{3}{*}{$\begin{array}{l}\text { Antibiotic sensitivity } \\
\text { of gastric culture }\end{array}$} & \multicolumn{4}{|c|}{ Number $=31$} \\
\hline & \multicolumn{2}{|c|}{ Sensitive } & \multicolumn{2}{|c|}{ Resistant } \\
\hline & $\mathrm{N}$ & $\%$ & $\mathrm{~N}$ & $\%$ \\
\hline Metronidazole & 0 & 0.0 & 31 & 100.0 \\
\hline Clarithromycin & 24 & 77.4 & 7 & 22.6 \\
\hline Amoxacillin & 21 & 67.7 & 10 & 32.3 \\
\hline Levofloxacin & 29 & 93.5 & 2 & 6.5 \\
\hline
\end{tabular}


Total patients with positive Helicopacterpylori Ag in stool and positive occult blood in stool $\mathrm{n}=50$
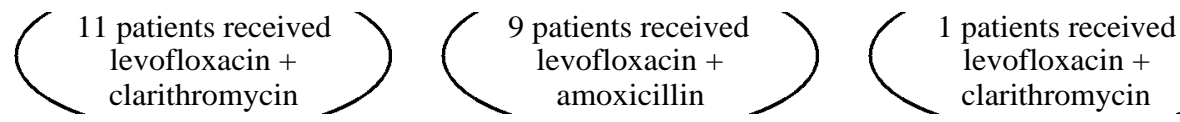

Fig. (1): Flow chart of patients.

Table (4): Antibiotic sensitivity of duodenal culture.

\begin{tabular}{lllll}
\hline & \multicolumn{4}{c}{ Number $=28$} \\
\cline { 2 - 5 } $\begin{array}{l}\text { Antibiotic sensitivity } \\
\text { of duodenal culture }\end{array}$ & \multicolumn{2}{c}{ Sensitive } & \multicolumn{2}{c}{ Resistant } \\
\cline { 2 - 5 } & $\mathrm{N}$ & $\%$ & $\mathrm{~N}$ & $\%$ \\
\hline Metronidazole & 0 & 0.0 & 28 & 100.0 \\
Clarithromycin & 20 & 71.4 & 8 & 28.6 \\
Amoxacillin & 20 & 71.4 & 8 & 28.6 \\
Levofloxacin & 27 & 96.4 & 1 & 3.6 \\
\hline
\end{tabular}

\section{Discussion}

The results of our study showed that, the age of the studied group was ranged from 1.50-17 years, with a mean of $7.37 \pm 3.72$ years, the male inour study was $40.0 \%$ and females was $60.0 \%$. In our results the clinical history showed that abdominal pain andloss of appetite were detected in $(96 \%)$ and $(64 \%)$ respectively, while jaundice, pallor, cyanosis, lower limb and upper limb edema were not detected in any patient. Inagreement with our study, Castillo-Montoya et al., [7] reported that the most common symptoms in their patients were epigastric abdominal pain in $93.5 \%$ and loss of appetite in $80.0 \%$. In our study it was found that $10.0 \%$ of patients had hepatomegaly, while $8.0 \%$ of patients had splenomegaly in agreement with Seo et al., [8] who reported that hepatomegalywas detected in $9 \%$ while thesplenomegaly was detected in $9 \%$ of $\mathrm{H}$. Pylori cases. In our study endoscopic examinationreveals that, gastritis, esophagitis, incompatantcardia, gastric nodularity and hiatus hernia were detected in (98\%), (36\%),
$(32 \%),(26 \%)$ and $(22 \%)$ for each respectively, while gastric ulcer andduodenal ulcer were absent in all patients. In agreement with Mandal et al., [9], who reported erythematous antral gastritis in $(40.7 \%)$ followed byerosive gastritis in $(30.1 \%)$, pangastritisin $(8.8 \%)$, duodenal ulcer in $(11.5 \%)$, gastric ulcer in (8\%) and erosive fundal gastritis in $(1.8 \%)$ in their patients. Histopathological examination of gastric and duodenal biopsies reveled that, lymphocytes infiltrations plasma cells infiltrations epithelial edema and eosinophils infiltrations were detected in (90\%), (88\%), (86\%) and $(86 \%)$ for each respectively, while activity of $\mathrm{H}$. Pylori ware found in only in $(60 \%)$ of patients. No dysplasia or metaplasia were found. This differences may be due to change in the environment. Mandal et al., [9] published achronic active gastritis (CAG) was observed in $\mathrm{H}$. Pylori infection and was significantly higherin comparison to $\mathrm{H}$. Pylori negative subjects. In our study, the antibiotic sensitivity of gastric cultures shows that Levofloxacin had the highest antibiotic sensitivity (93.5\%), followed by, clarithromycin and amoxicillin in (77\%) and (67.7\%) respectively. On the other hand, $100 \%$ of cases were resistant to the Metronidazole, while duodenal cultures, Levofloxacin had the highest antibiotic sensitivity (96.4\%), followed by, clarithromycin and amoxicillin in (71.4\%) for each. While, $100 \%$ of cases were resistant to the Metronidazole. All patientsreceived PPI and Levofloxacin, but about $59 \%$ and $30 \%$ of patients received Amoxacillin and Clarithromycin respectively. No one received Metronidazole as a treatment. Primary resistance of H. Pylori to CLA was 
investigated among Portuguese and Austrian children. $35 \%$ of Portuguese were resistance to CLA, where as resistance among the Austrian children was $34 \%$ [10]. This agreement with Butenko et al., 2017 who reported in their multicenter study, that $20 \%$ of European children resistance to CLA. Several studies on the antimicrobial resistance of H. Pylori among European children have shown primary resistance to MET at $10 \%-35 \%$, to AMO at $0 \%-1 \%$, and to LEV at $0.2 \%-0.6 \%$, where as resistance to tetracycline has not generally been reported [11]. Butenko et al., [3] studied resistance to MET, CLA, and AMO using H. Pylori isolates from children before and after treatment. The rate of MET and CLA resistance before treatment was $35 \%$ and $9 \%$, and 6 weeks after treatment it was $48 \%$ and $18 \%$, respectively.

\section{Conclusion:}

H. Pylori a in stool should not be used alone for diagnosis of $\mathrm{H}$. Pylori infection, treatment of Helicobacter Pylori should be tailored according to tissue culture and sensitivity.

\section{References}

1- GOLD B.D., GILGER M.A. and CZINN S.J.: New diagnostic strategies for detection of Helicobacter pylori infection in pediatric patients. Gastroenterology \& hepatology, 10: 1, 2014.

2- AGBOR N.E., ESEMU S.N., NDIP L.M., TANIH N.F., SMITH S.I. and NDIP R.N.: Helicobacter pylori in patients with gastritis in West Cameroon: Prevalence and risk factors for infection. BMC research notes, 11: 559, 2018.

3- BUTENKO T., JEVERICA S., OREL R. and HOMAN M.: Antibacterial resistance and the success of tailored triple therapy in Helicobacter pylori strains References - 92 - isolated from Slovenian children. Article in Helicobacter. June 2017. DOI: 10. 111 1/hel. 12400, 2017.
4- SÁNCHEZ DELGADOA J., GARCÍA-IGLESIAS P., TITÓ L., PUIGD I., PLANELLAF M., GENÉB E., et al.: Update on the management of Helicobacter pylori infection. Gastroenterol. Hepatol., 41: 272-80, 2018.

5- LAVING A., KAMENWA R., SAYED S., KIMANG'A A.N. and REVATHI G.: Effectiveness of sequential v. standard triple therapy for treatment of Helicobacter pylori infection in children in Nairobi, Kenya Vol. 103, No. 12 SAMJ, 2013.

6- MALFERTHEINER P., MEGRAUD F., O'MORAIN C., et al.: Management of Helicobacter pylori infection: The Maastricht IV/Florence Consensus Report. Gut., 61: 64664, 2012.

7- CASTILLO-MONTOYA V., RUIZ-BUSTOS E. VALENCIA-JUILLERAT M., ÁLVAREZHERNÁNDEZ G. and SOTELO-CRUZ N.: Detection of Helicobacter pylori in children and adolescents using the monoclonal coproantigen immunoassay and its association with gastrointestinal diseases. Cirugía y Cirujanos, 85 (1): 27-33, 2017.

8- SEO J.W., PARK J.W., SHIN T.S. and KIM J.G.: The analysis of virulence factors and antibiotic resistance between Helicobacter pylori strains isolated from gastric antrum and body. BMC Gastroenterology, 19: 140, 2019.

9- MANDAL A.K., KAFLE P., PURI P., CHAULAGAI B., SIDHU J., HASSAN M., PAUDEL M., KANTH R. and GAYAM V.: An association of Helicobacter pylori infection with endoscopic and histological findings in the Nepalese population. Journal of Family Medicine and Primary Care, 8: Issue 3, 2019.

10-MANFREDI M., GISMONDI P., MAFFINI V., BIZZARRI B., FORNAROLI F., MADIA C., et al.: Primary Antimicrobial Susceptibility Changes in Children with Helicobacter pylori Infection over 13 Years in Northern Italy. Gastroenterol. Res. Pract., 2015: 717349. doi: 10.1155/ 2015/717349, 2015.

11-VILAICHONE R.K., RATANACHU-EK T., GAMNARAI P., et al.: Extremely high prevalence of metronidazoleresistant Helicobacter pylori strains in References - 100 = mountain people (Karen and Hmong) in Thailand. Am. J. Trop. Med. Hyg., 94: 717-20, 2016. 


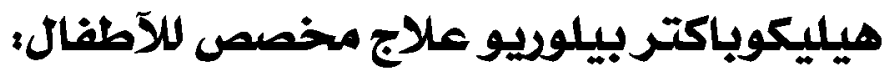

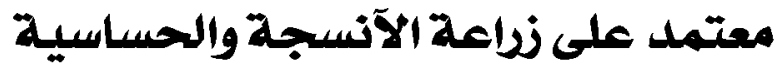

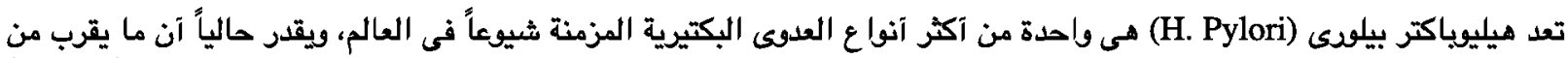

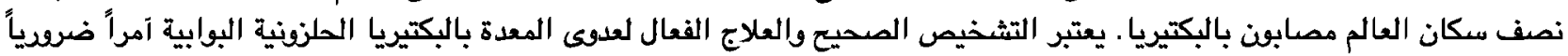

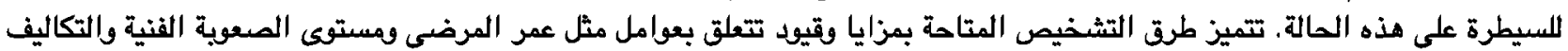

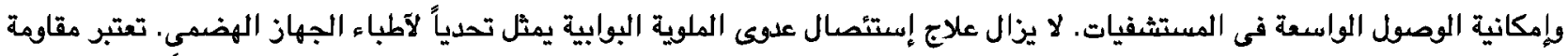

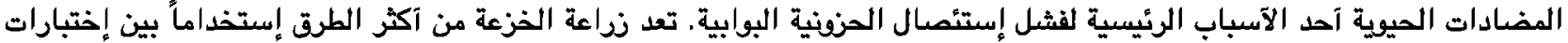
الحساسية لمضادات الميكروبات.

الهدف من العمل: كان الهدف من هذا العمل هو تحديد العلاج المناسب لعلاج بكتيريا الطلزونية البوابية وفقاً لثقافة الآنسجة المعدية الإثنى عشرية وحساسية المضادات الحيوية.

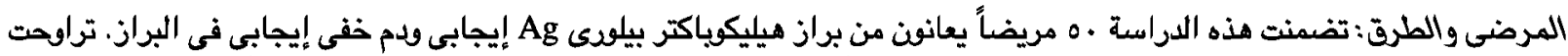

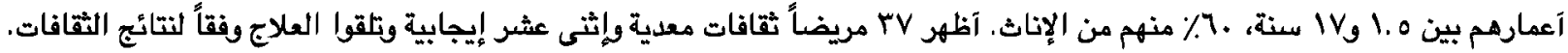

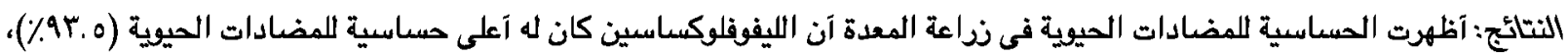

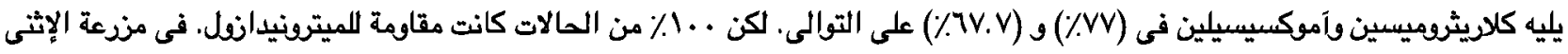

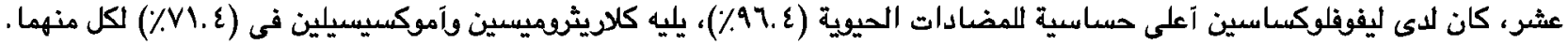

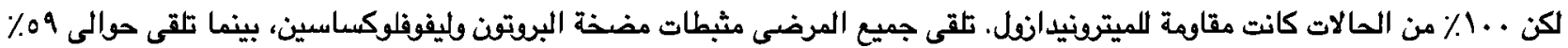

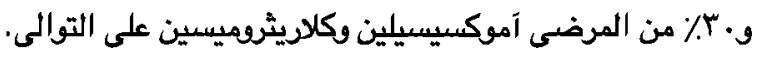

الإستتاج: يجب آن يتم تكييف علاج هيليوياكتر بيلورى وفقاً لثقافة الآنسجة وحساسيتها. 